\title{
Submissão e aprovação de protocolo de pesquisa em um comitê de ética: percepções dos pesquisadores
}

\section{Submission and approval of research protocol in a Research Ethics Board: researchers' perceptions}

\author{
Antonia Siomara Rodrigues Silva \\ antonia.siomara@stacasa.com.br \\ Regina Célia Carvalho da Silva \\ Universidade de Fortaleza, Fortaleza, Ceará, Brasil \\ regcelcarvalho@ig.com.br \\ Francisco Rosemiro Guimarães Ximenes Neto \\ UVA/FIOCRUZ, Sobral, Ceará, Brasil \\ rosemironeto@gmail.com
}

Universidade Estadual Vale do Acaraú, Sobral, Ceará, Brasil

\section{Eliany Nazaré Oliveira}

UVA/FIOCRUZ, Sobral, Ceará, Brasil

elianyy@hotmail.com

Aprovação pelo CEP da Universidade Estadual Vale do Acaraú por Parecer 339.

Resumo: O objetivo deste estudo foi analisar a percepção do usuário do Comitê de Ética em Pesquisa (CEP) acerca da submissão do Protocolo de Pesquisa. Esse é um estudo exploratório-descritivo com abordagem qualitativa realizado no CEP. Os sujeitos foram os estudantes de graduação e pós-graduação usuários do CEP. Utilizamos entrevista semi-estruturada e análise do discurso do sujeito coletivo. Verificou-se que a maioria dos sujeitos desconhece o processo de construção da folha de rosto e não realiza leitura da Resolução CNS 196 de 1996. Embora submetam os trabalhos por obrigatoriedade da Universidade, reconhecem que o CEP proporciona respaldo científico para a pesquisa.

Palavras chave: Comitês de ética em pesquisa, bioética, universidades.

\footnotetext{
Abstract: The objective of this study was to analyze the perception of the user of the Research Ethics Board (REB) concerning the Research Protocol submission. This is an exploratory-descriptive study with a qualitative approach conducted inside the REB. The participants were graduation and post-graduation students, users of the REB. We used semi-structured interviews and
} 
analysis of the collective subject's speech. It was verified that most of the subjects ignore the elaboration process of the coversheet, and do not read the Resolution CNS 196 of 1996. Even though they submit the protocols as a University requirement, they recognize that the REB provides scientific support for their research.

Key words: Research ethics boards, bioethics, universities.

\section{Introdução}

As pesquisas realizadas no campo da saúde devem ser movidas pelos princípios éticos objetivando aumentar o bem estar do ser humano. Porém, apesar dos importantes benefícios que traz à humanidade, ainda se faz necessária a existência e orientação ética, verificadas pelos históricos abusos realizados pelos pesquisadores, muitos dos quais chocaram a sociedade em tempos não longínquos (1).

Pensar a ética nos tempos atuais é extremamente importante porque não é usual. Outros elementos de referência costumam tomar o seu lugar quando se contempla o comportamento da sociedade em diversos campos, como a política, a propaganda, as artes e as ciências (2). Nesse sentido, durante a formação acadêmica, cotidianamente, nos vemos frente a conflitos éticos que são, de algum modo, agravados pelas divergências em relação aos princípios, valores e crenças expressas de diferentes modos (3).

A pesquisa é um processo de construção do conhecimento que tem como metas principais gerar novo conhecimento e/ou corroborar ou refutar algum conhecimento preexistente (4). É basicamente um processo de aprendizagem tanto do sujeito que a realiza, quanto da sociedade na qual esta se desenvolve. Quem realiza a pesquisa pode, num nível mais elementar, aprender as bases do método científico ou, num nível mais avançado, aprender refinamentos técnicos de métodos já conhecidos. A sociedade e a comunidade beneficiam-se com a aplicação do novo conhecimento gerado pelos sujeitos que a compõem.

Assim sendo, quando falamos em pesquisas, referenciamos a universidade -Instituição de Ensino Superior e, portanto local onde se pesquisa livremente-, sem nenhum outro tipo de limite que não seja à vontade do pesquisador. Pesquisas são realizadas em prol do conhecimento científico; outras, no entanto, são feitas apenas no intuito do 
cumprimento de normas para a conclusão dos cursos.

A universidade tem por missão formar profissionais e técnicos com competência, visão crítica e perspectiva humanística, sendo a ética importante em toda essa concepção. Nas comunidades acadêmicas, todas as relações entre os membros dos diferentes segmentos -docentes, discentes e funcionários--, exigem uma base ética (5).

A história das pesquisas envolvendo seres humanos está marcada por situações consideradas abusivas para com os sujeitos envolvidos nos estudos realizados. Inicialmente, os pesquisadores utilizavam como sujeitos dos experimentos não somente eles próprios, mas também seus familiares e vizinhos. Em consequência da divulgação das atrocidades ocorridas nos campos nazistas e da realização do julgamento de Nuremberg, promovido pelos Estados Unidos, foi elaborado o primeiro documento internacional, conhecido como o Código de Nuremberg. Mas tarde, por volta de 1964, o crescimento do número de pesquisas terapêuticas realizadas por médicos e a repercussão que isso poderia acarretar sobre a prática profissional, levou a Associação Médica Mundial a elaborar e promulgar a Declaração de Helsinque, que registrava a importância de se respeitar os seres humanos em sua totalidade e defender os sujeitos em situação de vulnerabilidade (6).

O Brasil conta, atualmente, com cerca de 550 Comitês de Ética em Pesquisa (CEP) credenciados, e a estrutura do sistema CONEP/CEP pode ser considerada um exemplo para países desenvolvidos e em desenvolvimento. Estima-se que mais de 5.000 profissionais e representantes da comunidade estejam envolvidos nas discussões relativas aos aspectos éticos e metodológicos de projetos de pesquisa -pelo menos uma vez por mês-. Supõe-se que cerca de 600.000 sujeitos que participam de estudos realizados no país estejam protegidos pelo Sistema CONEP/CEP (6).

Este estudo tem como objetivo geral analisar a percepção do usuário do CEP, acerca do processo de submissão do Protocolo de Pesquisa no CEP. Os objetivos específicos são: traçar o perfil sociodemográfico dos usuários do CEP; averiguar os conhecimentos dos participantes da pesquisa acerca da importância do CEP; e identificar as dificuldades e formas de enfrentamento do pesquisador ao submeter seu protocolo de pesquisa ao CEP. 


\section{Metodologia}

Estudo exploratório-descritivo, com abordagem qualitativa, realizado no CEP de uma universidade do Norte Cearense, entre os meses de novembro de 2007 e maio de 2008.

Os sujeitos foram os usuários, estudantes de graduação e pós-graduação (lato-sensu e stricto sensu) do CEP. Com relação aos critérios de inclusão e exclusão referente aos usuários, foram incluídos em nossa amostra aqueles que se dirigiram à sede do CEP no período correspondente à coleta dos dados e que aceitaram participar do estudo após assinarem o Termo de Consentimento Livre e Esclarecido.

Para a coleta de dados utilizamos como instrumento um roteiro de entrevista semi-estruturada, as entrevistas foram gravadas e transcritas posteriormente mediante aceitação por parte dos sujeitos do estudo. Para análise das entrevistas, foi utilizada a técnica do discurso do sujeito coletivo (DSC) (7) que permite a sistematização e análise detalhada do conteúdo dos dados coletados.

Buscando o alcance dos objetivos definidos para o presente estudo, são apresentados, a seguir, os discursos que ilustram como os pesquisadores usuários do CEP se posicionam frente ao processo de submissão de seu protocolo de pesquisa. Para coletarmos as informações entrevistamos 40 pesquisadores que submeteram suas pesquisas ao CEP. A entrevista continha seis perguntas abertas, além de dados de identificação. A análise dos discursos está fundamentada em cinco categorias, além de um perfil.

Os procedimentos de construção do DSC utilizados nesta pesquisa obedeceram aos seguintes passos: copiar, integralmente, o conteúdo de todas as entrevistas; identificar, destacar e agrupar as ideias centrais de mesmo sentido; criar uma ideia central ou ancoragem síntese; e construir o DSC.

O estudo incorporou os quatro princípios da bioética de acordo com as diretrizes e normas da Resolução CNS 196 de 1996 (8) (autonomia, beneficência, não-maleficência, e justiça), e foi submetido à apreciação do CEP da UVA. 


\section{Resultados e Discussão}

\section{Caracterização dos sujeitos do estudo}

De acordo com as variáveis sociodemográficas, a maioria dos pesquisadores pertencia ao sexo feminino (perfazendo 70\% dos entrevistados). A idade média das mulheres foi de 28 anos; a dos homens foi de 34 anos. Quanto à formação acadêmica, 82,5\% dos participantes vinham da área da saúde (enfermagem, psicologia ou medicina) e 7,5\% de outras áreas do conhecimento (matemática, letras e pedagogia).

No que se refere ao nível de formação: 50\% eram de graduação, $30 \%$ de pós-graduação (25\% do tipo latu sensu e 5\% do tipo strictu sensu), e o $20 \%$ restante correspondia a pesquisas institucionais, financiadas por instituições de fomento à pesquisa como o Conselho Nacional de Desenvolvimento Científico e Tecnológico (CNPq) e a Fundação Cearense de Apoio e Desenvolvimento da Pesquisa (FUNCAP). Em relação ao vínculo, 90\% dos pesquisadores estavam vinculados à universidade do CEP e 10\% a outras instituições de nível superior.

\section{Abstração dos discursos}

Preenchimento da Folha Rosto no Sistema de Informação sobre Ética em Pesquisa Envolvendo Seres Humanos (SISNEP)

Embora a Folha de Rosto (FR) seja considerada como um documento necessário e indispensável ao protocolo, a maioria dos sujeitos entrevistados afirmou não conhecer -ou conhecer parcialmenteseu processo de construção. Alguns atestaram a não participação no preenchimento da FR ao compromisso do orientador -pesquisador responsável- em preenchê-la.

DSC - 1 Tive, principalmente na parte que ele perguntava das três amostras, no local, no Brasil e no mundo, tem perguntas que se têm dúvidas para responder. No roteiro que a gente recebe não diz como preencher, só como acessar. Eu tive que ter toda uma aprendizagem. O acesso a página, a linguagem era complicada, não era acessível, com questionamentos des- 
necessários. Quando eu comecei a ler as perguntas eu não sabia como responder e terminei fazendo aqui no comitê, fiquei com dificuldade com relação à instituição (sediadora e vinculada), e em relação aos sujeitos da pesquisa.

Ideias Centrais: dúvidas; ter toda uma aprendizagem.

DSC 2 - Eu não participei da construção, não construí a folha de rosto, foi minha orientadora, se eu fosse preencher sozinha eu teria dificuldade na linguagem, eu não sabia o que era folha de rosto e nem participei do preenchimento. A verdade é que eu nunca fiz uma folha de rosto, quem fez foi o meu orientador.

Ideia Central: não participou da construção; o orientador quem preenche.

As dificuldades apresentadas pelos usuários do CEP são empecilhos para o bom desenvolvimento do processo de pesquisa. Houve dúvidas sobre a definição exata do que representa instituição sediadora e vinculada à pesquisa.

No DSC 2, percebemos que há um protagonismo do orientador na confecção da FR; podemos ressaltar que em nível de graduação isto é louvável desde que o orientador exija a participação do orientando neste processo, uma vez que assim o orientando poderá apreender e compreender todo o fluxo de preenchimento da folha de rosto.

Em relação às pesquisas de pós-graduação, parece haver ainda em alguns casos o protagonismo do orientador no preenchimento da folha em questão. Para amenizar essas dificuldades, sugerimos que os orientadores primem por uma orientação mais detalhada, mais específica e caminhem junto com seus orientandos, no sentido de esclarecer a importância da submissão de suas pesquisas a um CEP, explicando todo o trâmite do processo de submissão.

Para o preenchimento da folha de rosto, é necessário que o pesquisador responsável seja cadastrado no SISNEP. Criado no ano 2000, esse constitui uma ferramenta que trouxe agilidade e transparência para o dia-a-dia dos pesquisadores que atuam no Brasil e, ao mesmo tempo, a garantia à população de mecanismos para exercer o controle social no campo da ciência (9). 


\section{Leitura da Resolução do CNS No 196/1996}

A Resolução CNS 196 de 1996, denominada Diretrizes e Normas Regulamentadoras de Pesquisas Envolvendo Seres Humanos, constitui documento fundamental de proteção aos sujeitos da pesquisa, sendo fundamentada nos principais documentos internacionais que emanaram declarações e diretrizes sobre pesquisas que envolvem seres humanos.

DSC 1 - Eu li uma parte, que fala dos quatro princípios fundamentais, beneficência, não-maleficência, justiça e autonomia, na íntegra mesmo não. Li, mas ficaram parágrafos incompreensíveis. Sou ex-membro do Comitê, isso ajudou na construção do meu projeto na forma de não ser indutivo. Confesso que li por cima, a gente teve uma disciplina no mestrado só voltada pra isso, e acabou contribuindo, mas eu não parei e li toda, não. Fiz uma breve leitura, não foi geral. Li, mas não completamente.

Ideia Centrais: breve leitura; leitura superficial.

DSC 2 - Não, não li essa resolução. Não tive acesso à resolução, eu não li essa lei

Ideia Central: não leu a Resolução.

O aprimoramento constante das normas para pesquisa envolvendo seres humanos firmou-se como marcante característica do meio científico brasileiro. Ao lado dos esforços intensos de manter espaços de grande reconhecimento em nível nacional e internacional, a nossa ciência e tecnologia revelam grande sensibilidade e compromisso social, com destaque para o respeito intransigente dos direitos de cidadania dos seres humanos, sujeitos das pesquisas. Esta explicitação consta das principais resoluções e normas do Conselho Nacional de Saúde, sobre a Ética nas Pesquisas que Envolvem Seres Humanos, que nos colocam hoje entre os países mais evoluídos neste nobre campo de atividades (10).

No DSC 1, notamos que muitos dos sujeitos da pesquisa, embora afirmarem a realização de uma leitura breve e superficial da resolução, desconhecem-na no seu verdadeiro papel. Afirmam encontrar 
na Resolução parágrafos incompreensíveis, ou terem lido apenas por fazer parte de seu cotidiano, como afirma uma entrevistada que teve uma disciplina no programa de mestrado que realizava.

No DSC 2, os entrevistados atestam a não leitura e até mesmo o não conhecimento dessa resolução, o que implica a falta de suporte necessário para a montagem do projeto e posterior realização da pesquisa.

A não leitura ou leitura superficial tem implicações negativas para a elaboração do protocolo de pesquisa, e principalmente para a sua implementação. Sabemos que é na resolução que estão disponíveis as orientações básicas quanto aos princípios éticos necessários ao pesquisador e sua relação com os sujeitos envolvidos no estudo. Sem o conhecimento consistente deste documento o projeto pode tornar-se inadequado eticamente.

\section{Justificativa para a Submissão do Protocolo de Pesquisa ao CEP}

A Resolução CNS 196 de 1996, item II, orienta que toda pesquisa envolvendo direta ou indiretamente seres humanos, realizada em qualquer área do conhecimento, deve ser pautada nos princípios éticos, incluindo o manejo de informações ou materiais. Assim, também são consideradas pesquisas envolvendo seres humanos as entrevistas, aplicação de questionários, utilização de bancos de dados e revisões de prontuários; essas pesquisas, no entanto, devem ser apresentadas a um CEP (8).

DSC 1 - Porque faz parte! Porque tinha que submeter, fui estimulada pela orientadora, mas se não fosse a monografia eu não entregaria aqui no CEP. É uma rotina para prosseguir o estudo. Me disseram que era necessário, eu achava que era obrigado por causa da monografia. A faculdade diz que tem que passar pelo comitê. A gente passa não por vontade própria, mas porque tem que passar. A gente ficou sabendo que precisaria como norma da instituição, pra ter o certificado de conclusão. Achei que era obrigatório, mas acho importante o parecer do comitê.

Ideia Central: submissão ao comitê para cumprir burocracia exigida.

DSC 2 - Por indicação do que era o Comitê de Ética. Porque 
todo projeto que envolva seres humanos tem que passar pelo comitê. Como essa pesquisa trabalha com seres humanos, eu decidi prezar sempre pelos princípios éticos. Por ter estado por dentro do processo do CEP e por acreditar que esse comitê ele é funcional, ele tem uma responsabilidade social, principalmente ética. Eu quero fazer uma coisa bem feita, aqui é seguro. Como é em saúde mental, então é uma população vulnerável, então me ajudou a própria necessidade mesmo. É importante ter outras pessoas avaliando o trabalho, vendo os erros, dando sugestões. Porque já que é uma pesquisa com entrevistas, com seres humanos, tem que ter esses critérios. Ideia Central: submissão ao CEP por ser uma pesquisa que envolve seres humanos.

O CEP, embora desempenhe um papel consultivo e educativo, procurando fomentar a reflexão em torno da ética na ciência, é visto por alguns usuários apenas como emissor de pareceres para permitir a realização da pesquisa, já que nos últimos anos instituições de ensino, órgãos de fomento à pesquisa e revistas científicas exigem a avaliação do estudo, ainda em sua fase de projeto, por um CEP (9).

No DSC 1, observamos que a maioria dos entrevistados desconhece o verdadeiro papel de um CEP, alegando submeter seus trabalhos apenas por ser obrigatório pela Universidade, para assim obter certificação de curso, e desconhecendo sua responsabilidade em trabalhar com humanos. Os entrevistados afirmaram também que a submissão era feita muitas vezes por incentivo do orientador da pesquisa, e/ou colegas de curso, porém não se tratava de decisão consciente.

A pesquisa em si é realizada com o objetivo de descobrir algo novo, ou para corroborar ou refutar algo já conhecido. A motivação básica que leva o sujeito a realizar uma pesquisa científica é o aprendizado, seja do método científico, seja das técnicas empregadas ou ainda do assunto em foco na pesquisa. Outros aspectos menos nobres como projeção acadêmica, titulação ou melhoria financeira são motivos que também levam o sujeito a realizar uma pesquisa (4).

Neste sentido, percebemos que há um aumento significativo de pesquisas realizadas no campo da saúde ou em outras áreas do conhecimento já que o ato de pesquisar vem sofrendo modificações positivas devido às crescentes discussões sobre a ética na pesquisa. 
O conceito de pesquisa é muito amplo, mas a característica básica de seu campo de atuação é produzir conhecimentos que possam trazer benefícios, tanto diretos como indiretos, à sociedade. É a busca de conhecimentos que possam nortear ações em diferentes áreas de atuação, visando à solução e o entendimento de questões em diversas naturezas (11).

Já no DCS 2 pudemos observar que cerca de 20\% dos entrevistados, embora sendo uma minoria, afirmou ser consciente de sua atitude em enviar seu trabalho ao CEP para apreciação ética, pois se tratava de uma pesquisa envolvendo seres humanos. Daí a necessidade de submeter a pesquisa a um CEP, visto que estudos desta natureza, envolvendo sujeitos ou coletividades, necessitariam desta anuência, para seguir todos os paramentos éticos e legais.

\section{Dificuldades para Submissão do Protocolo de Pesquisa ao CEP}

De acordo com a Resolução CNS 196 de 1996, o CEP somente deve receber protocolos de pesquisa adequadamente elaborados em português, contendo: folha de rosto devidamente preenchida e assinada; projeto de pesquisa completo, incluindo cronograma, orçamento e termo de consentimento livre e esclarecido e pós-informado; e curriculum vitae do pesquisador responsável e dos demais participantes.

A responsabilidade do pesquisador é indelegável, indeclinável e compreende aspectos éticos e legais.

DSC 1 - A questão do prazo e a burocracia que envolve o processo. Conseguir a assinatura da Folha de Rosto pelo responsável. Em relação ao TCLE e a FR, pensei que eram duas cópias e era apenas uma, não sabia se precisava assinar. As burocracias, tipo ofício para a instituição, Folha de Rosto, etc. Dificuldade em elaborar o projeto, a metodologia da pesquisa. Saber quais os documentos necessários para submissão da pesquisa.

Ideia Central: burocracias.

DSC 2 - Faltou uma divulgação, pelo menos algum papel num flanelógrafo. Falta de informação, não tem divulgação. A demora das informações chegarem lá no curso de Especialização. O CEP precisa ser divulgado mais, talvez ele tenha 
uma divulgação dentro do meio acadêmico, lá, pros alunos, mas pra quem já saiu algum tempo da Universidade e terminou há algum tempo, eles não sabem nada do comitê. Ideia Central: falta de divulgação.

No DSC2, constatamos que a maior dificuldade relatada pelos usuários deste CEP em submeter seu projeto, seria a falta de divulgação do próprio $\mathrm{CEP}$, em relação a sua função na Universidade, bem como as burocracias intrínsecas ao processo de submissão.

No DSC 1, as dificuldades abordadas pelos usuários do CEP em questão demonstram que o pesquisador ainda esbarra em critérios básicos diante do processo de pesquisa, como, por exemplo, a burocracia que envolve, julgando, muitas vezes, procedimento desnecessário. No entanto, a avaliação ética de um projeto de pesquisa em saúde baseia-se na qualificação do projeto de pesquisa, na experiência da equipe de pesquisadores envolvidos, na avaliação do risco-benefício envolvido, na informação precisa e detalhada ao sujeito da pesquisa e consequente obtenção do seu consentimento informado, e na prévia avaliação de possíveis efeitos da investigação pretendida (12).

O protocolo de pesquisa é um conjunto de documentos que o pesquisador prepara como parte do processo de elaboração de seu projeto de pesquisa. A preparação deste material é uma tarefa burocrática que causa descontentamento ao pesquisador, que se sente perdendo tempo valioso na juntada de documentos que, a primeira vista, parecem irrelevantes. O protocolo assim exigido visa garantir dois aspectos importantes: a cientificidade da pesquisa e sua eticidade (13) e permite que o pesquisador organize sua proposta de trabalho, como também, que o CEP desempenhe sua função de controle social.

Já no DSC 2, os entrevistados expressaram que há uma falta de divulgação das atividades do CEP, e que o mesmo deve procurar atender e dar orientação para os pesquisadores antes da apresentação do protocolo, assim como divulgar sua missão na universidade na comunidade, tendo uma relação transparente, objetiva e acolhedora, assessorando o pesquisador nas suas dúvidas.

$\mathrm{Na}$ tentativa de amenizar essas dificuldades, sugerimos que o CEP, junto com o orientador e a universidade, exerça seu papel de 
educação continuada junto aos pesquisadores, promovendo a discussão dos aspectos éticos das pesquisas, bem como ofertando atividades, como seminários, palestras, jornada, cursos de extensão, entre outros. O CEP deve também assegurar aos usuários informações de todo o processo de submissão do protocolo, conscientizando que todos os documentos são necessários para a apreciação, tanto do ponto de vista ético, como metodológico.

\section{Vantagem em ter um trabalho apreciado por um CEP}

Ao interrogar os sujeitos da pesquisa sobre as possíveis vantagens em submeter um protocolo de pesquisa a um CEP, a maioria dos entrevistados enfatizou que só submete seus projetos porque gostaria de publicá-los futuramente.

DSC 1 - A vantagem é que eu posso publicar meu projeto e também porque a pesquisa fica registrada. A vantagem é que o nosso trabalho fica sério, tem respaldo e gente pode publicar. Eu terei um direcionamento melhor para preparar minha monografia, além da segurança, agente recebe como se fosse um parecer que isso vai poder ser publicado, isso é um incentivo. Algumas pessoas de fora vão olhar com outros olhos pro nosso trabalho, sobre a pesquisa e contribuir. A credibilidade com a sua pesquisa, você vai está fazendo uma coisa seguindo os critérios nacionais, então se você publicar em qualquer lugar todos vão saber que você fez tudo certinho dentro dos critérios, não foi uma pesquisa aleatória.

Ideias Centrais: seriedade da pesquisa; respaldo científico; possibilidade de publicação.

DSC 2 - Dá mesmo essa segurança em você não tá cometendo nenhuma arbitrariedade, nenhum delito, eu acho que lhe deixa mais seguro pra realizar sua pesquisa. Enfim, seria a garantia de que seu trabalho não está ferindo com a ética cientifica.

Ideia Central: garantia de que a pesquisa não está ferindo a ética cientifica.

Ter uma pesquisa respaldada em critérios éticos foi a vantagem citada com maior ênfase pelos usuários do CEP. Saber que se está desenvolvendo uma pesquisa dentro dos parâmetros éticos e legais, 
torna o trabalho sério, além de proteger os participantes do estudo. Outras vantagens como possibilidade de publicação, credibilidade, seriedade, segurança e incentivo, também foram enfatizadas pelos usuários do CEP.

Salientamos que além de todas as vantagens citadas, o pesquisador precisa estar convicto da necessidade da submissão do projeto ao CEP pelo fato de sua pesquisa envolver seres humanos.

Um papel fundamental a ser desenvolvido pelo CEP local deve ser o de promover a formação e educação continuada de seus membros, assim como a dos pesquisadores e sujeitos de pesquisa envolvidos com a instituição da qual ele faz parte (9). É importante que o CEP disponibilize aos próprios membros e aos pesquisadores, endereços eletrônicos referentes ao tema da ética em pesquisa, estando sempre aberto para receber sugestões e incorporações advindas dos pesquisadores (14).

O papel educativo deve ser desempenhado mediante a realização de reuniões, seminários, mesas-redondas, grupos de discussão, criação de pagina eletrônica (site), e outros meios que possibilitem reflexão e discussão de temas éticos, casos com dilemas específicos e situações conflituosas. Deve ser estimulada a criação de cursos básicos sobre "ética em pesquisa com seres humanos" para pesquisadores institucionais, estudantes de graduação e pós-graduação, e representantes dos usuários, por meio de diversas formas de representação desenvolvidas na atual dinâmica social: associações, organizações não-governamentais, etc. (9).

\section{Considerações Finais}

O CEP é visto, na maioria das vezes, apenas como órgão emissor de parecer, perdendo sua verdadeira missão dentro e fora da universidade: a de órgão facilitador e norteador para a realização de estudos que envolvam seres humanos, procurando fomentar a reflexão em torno da ética na ciência.

Ao final desse estudo, pudemos perceber que o pesquisador ainda esbarra em critérios básicos diante do processo de pesquisa, convivendo com uma situação constantemente angustiante quando o fator é submissão de seu protocolo de pesquisa ao CEP, pois enfrenta, além de uma burocratização, a falta de informações quanto 
à data de reuniões, documentação necessária e prazo para entrega dos pareceres consubstanciados.

São necessárias ações de caráter educativo para os pesquisadores, a fim de tornar mais claro o papel do CEP como defensor dos sujeitos das pesquisas.

Este artigo foi organizado a partir de uma pesquisa mais ampla intitulada "Análise dos Protocolos de Pesquisa Apreciados pelo Comitê de Ética em Pesquisa da Universidade Estadual Vale do Acaraú (UVA)", que contou com apoio financeiro da FUNCAP.

\section{Referências}

1. Fortes PAC. Ética e Saúde: questões éticas, deontológicas e legais, tomada de decisão, autonomia e direitos do paciente, estudos de caso. São Paulo: EPU; 1998.

2. Manzatto A. Pesquisa e ética na universidade. PUC viva Revista. 2006; 7:11-18.

3. Fernandes MFP, Freitas GF. A construção do conhecimento do graduando de enfermagem: uma abordagem ético-social. Rev. Bras. Enferm. fev. 2007; 60(1):62-67.

4. Clark OAC, Castro AA. A pesquisa. São Paulo, Pesqui Odotol Bras. 2003; 17 (slup.1):67-9.

5. Wanderley LEW. Ética e Universidade. Ética em Pesquisa. jul./set. 2006; 7(27):62-66.

6. Diniz D, Guilhem D, Schüklenk U (organizadores). Ética na pesquisa: experiência de treinamento em países sul-africanos. Brasília: LetrasLivres/ Editora UnB; 2005. 192 pp.

7. Lefèvre F, Lefèvre AMC. Discurso do sujeito coletivo: um novo enfoque em pesquisa qualitativa (desdobramentos). Caxias do Sul (RS): EDUCS; 2003.

8. Brasil. Resolução n ${ }^{\circ} 196$, de 10 de outubro de 1996. Diretrizes e normas regulamentadoras de pesquisas envolvendo seres humanos. Conselho Nacional de Saúde - Comissão Nacional de Ética em Pesquisa. Brasília, DF. Diário Oficial da União de 12 de novembro de 1996.

9. Brasil. Ministério da Saúde. Manual Operacional para Comitês de Ética em Pesquisa. Brasília-DF, Conselho Nacional de Saúde - Comissão Nacional de Ética em Pesquisa; 2003.

10. Santos BS. Um discurso sobre as ciências. São Paulo: Cortez; 2003.

11. Fortes PAC, Zoboli ELP (organizadores). Bioética e saúde pública. São Paulo: Loyola; 2003. 167p.

12. Muccioli C, Dantas PEC, Campos M, Bicas HEA. Relevância do Comitê 
de Ética em Pesquisa nas publicações científicas. Arq. Bras. Oftalmol, 2008; 71(6): 773-774. http://www.scielo.br/scielo.php?Script $=$ sci arttext $\&$ pid $=$ S0004-27492008000600001\&lng $=$ en (acesso 10/dez/2008).

13. Martin LM. Ética em Pesquisa: uma perspectiva brasileira. In. Brasil. Ministério da Saúde. Secretaria de Ciência, Tecnologia e Insumos Estratégicos. Departamento de Ciência e Tecnologia. Capacitação para Comitês de ética em Pesquisa - CEPs. v.1: Brasília: Ministério da Saúde; 2006.

14. Tomanik EA. A ética e os comitês de ética em pesquisa com seres humanos. Psicol. estud. 2008; 13(2):395-404. http:// www.scielo.br/scielo.php? script =sci_arttext\&pid $\quad=\mathrm{S} 14$ $13-73722008000200023 \& \operatorname{lng}=\mathrm{en} \& \mathrm{nrm}=$ iso $>($ acesso $10 / \mathrm{Jun} / 2008)$

Recebido em: 05/09/2013 Aprovado em: 14/12/2013 